\title{
The Full Width Half Maximum technique is superior for LGE quantification regardless of its aetiology
}

\author{
Andrew S Flett*1, Jonathon M Hasleton ${ }^{1}$, Giovanni Quarta ${ }^{1}$, \\ Derek Hausenloy ${ }^{1}$, Vivek Muthurangu ${ }^{2}$ and James C Moon ${ }^{1}$
}

Address: ${ }^{1}$ The Heart Hospital, London, UK and ${ }^{2}$ Great Ormond Street Hospital, London, UK

* Corresponding author

from 13th Annual SCMR Scientific Sessions

Phoenix, AZ, USA. 21-24 January 2010

Published: 21 January 2010

Journal of Cardiovascular Magnetic Resonance 20 I0, I2(Suppl I):O4I doi:I0.I I86/I532-429X-I2-SI-O4I

This abstract is available from: http://jcmr-online.com/content/I2/SI/O4 I

(c) 2010 Flett et al; licensee BioMed Central Ltd.

\section{Introduction}

No consensus exists on how to quantify late gadolinium enhancement (LGE) even though it is now the gold standard for the assessment of focal myocardial fibrosis. SCMR official reporting recommendations suggest that LGE be defined as signal intensity $2 \mathrm{SD}$ above remote myocardium. However, 3, 4, 5 or $6 \mathrm{SD}$, manual quantification and the Full Width Half Maximum (FWHM) technique are also used, with the FWHM technique reported to be accurate in an animal infarct model.

\section{Purpose}

We sought to compare the seven LGE quantification techniques across the spectrum of disease: acute MI (AMI), chronic MI (CMI) and hypertrophic cardiomyopathy (HCM). We compared means and reproducibility.

\section{Methods}

53 patients with three LGE etiologies (AMI, $\mathrm{n}=18$; CMI, $\mathrm{n}=19, \mathrm{HCM}, \mathrm{n}=16$ ) were scanned for LGE. \%LGE was quantified per slice and for the whole heart using 7 different techniques (manual quantification, FWHM, 6,5,4,3,2 SDs) with inter- and intra-observer reproducibility and \%LGE assessed. After manual epi-endocardial segmentation, automated analyses were performed using macros in ImageJ (freely downloadable) with manual adjustment prior to output to include MVO as infarction, and to exclude blood pool/pericardial artifacts. \%LGE by each method was compared using a one-way repeated measure ANOVA with Bonferroni post-hoc analysis; Reproducibil- ity by intra-class correlation coefficient (ICC) \& $(\zeta)$ w and the significance of reproducibility differences by a Martin Bland technique Figures 1, 2 and 3.

\section{Results}

\%LGE varied substantially with the quantification method used. FWHM, manual and 6 or 5SD techniques gave statistically similar means in the 3 clinical scenarios. The 2SD technique generated \%LGEs up to $2 \times$ higher than FWHM, 6SD and manual techniques, particularly in HCM. The inter-observer and intra-observer reproducibility of all LGE techniques were worse in HCM than AMI and CMI. The FWHM technique was the most reproducible technique in all 3 conditions compared to any other technique ( $\mathrm{p}<0.001)$. In AMI and HCM, manual quantification was the least reproducible technique.

\section{Conclusion}

Across the spectrum of clinical disease in which LGE quantification is important, the FWHM technique for LGE quantification gives \%LGE mean results similar to manual quantification and has by far the best reproducibility regardless of underlying aetiology. SCMR recommendations for using the 2SD threshold technique should be reviewed. 


\section{Mean Percentage LGE area by Quantification Technique}

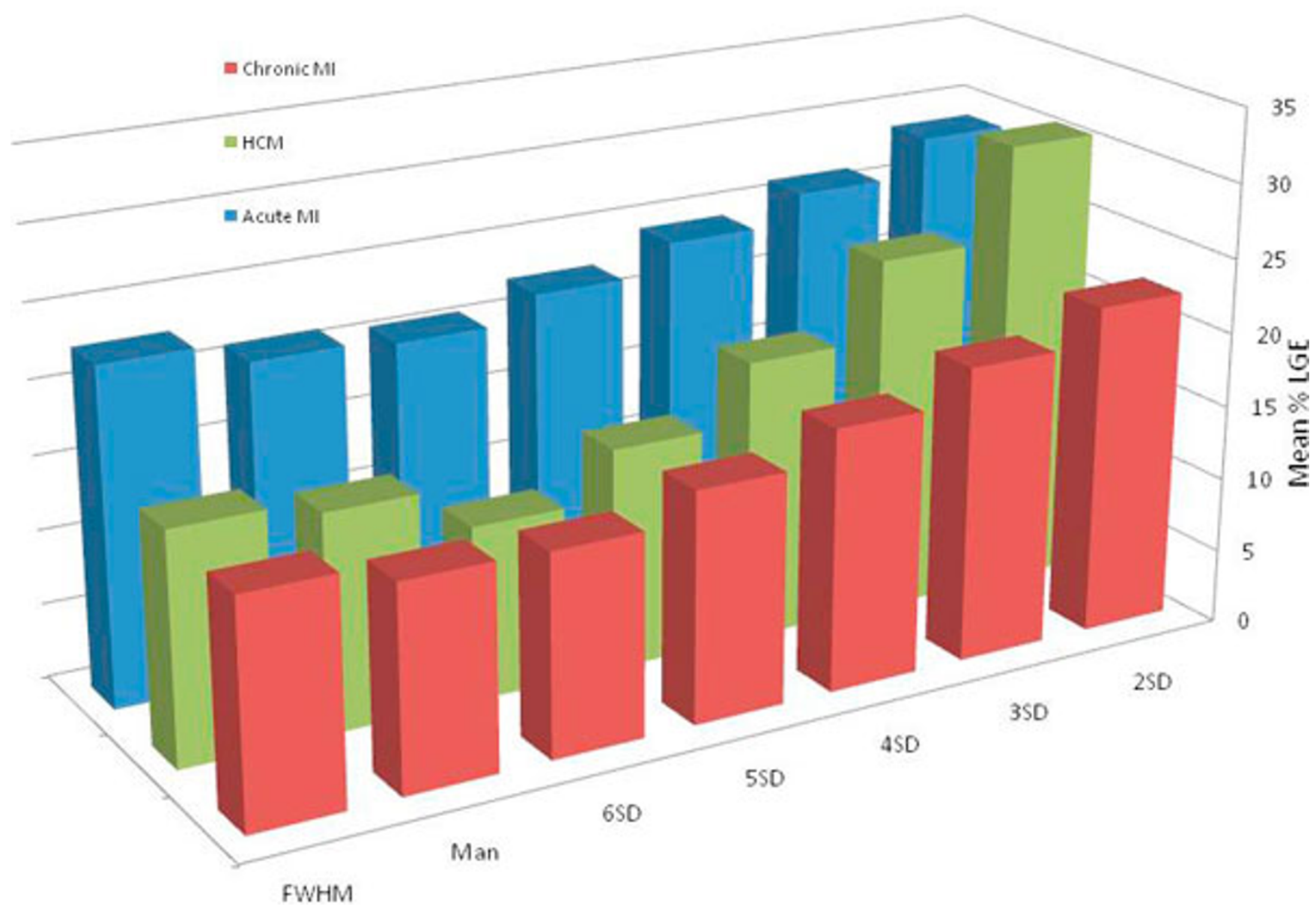

Figure I 


\section{Measurement Error by LGE Quantification Technique}

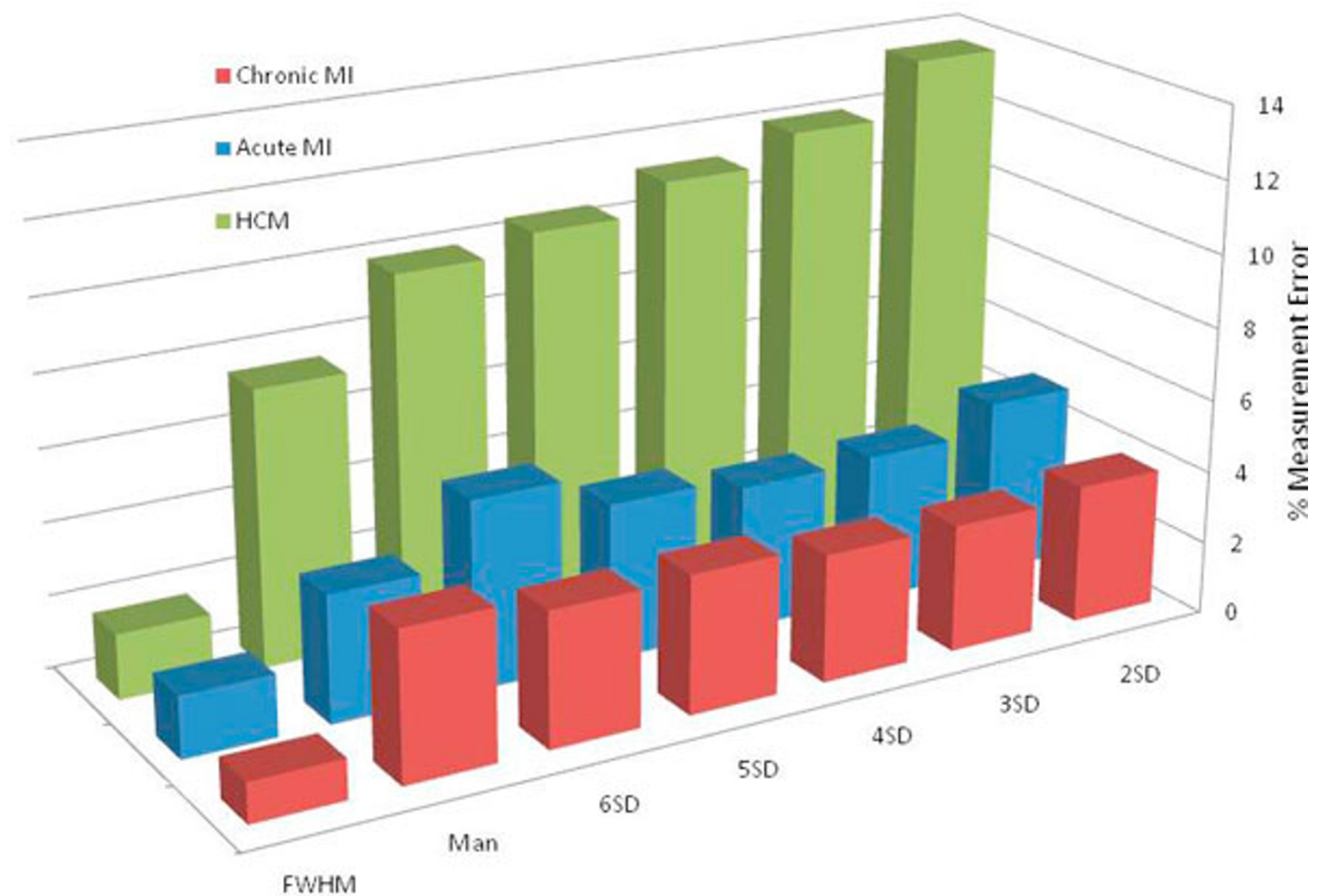

Figure 2 

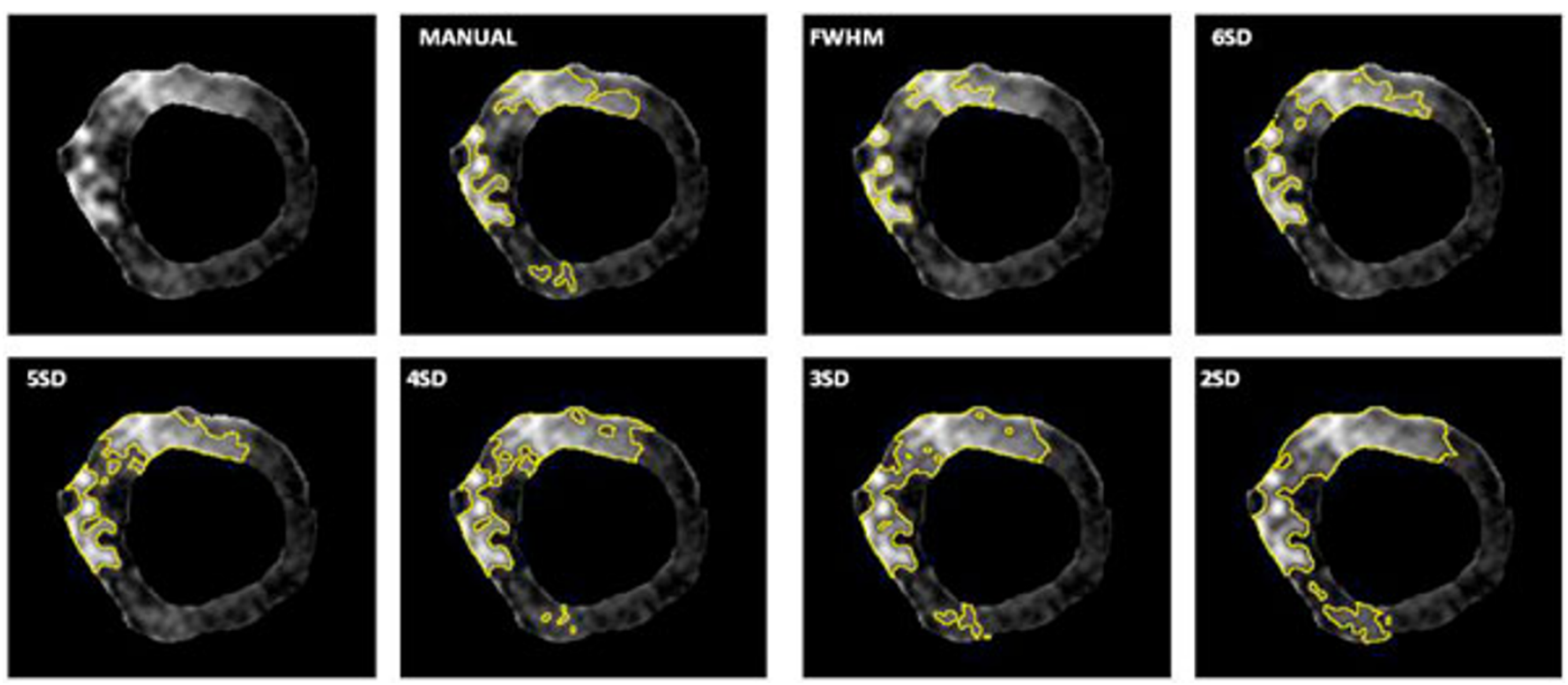

Figure 3

Publish with Bio Med Central and every scientist can read your work free of charge

"BioMed Central will be the most significant development for disseminating the results of biomedical research in our lifetime. "

Sir Paul Nurse, Cancer Research UK

Your research papers will be:

- available free of charge to the entire biomedical community

- peer reviewed and published immediately upon acceptance

- cited in PubMed and archived on PubMed Central

- yours - you keep the copyright 